\title{
VISCOSITY, DENSITY AND ULTRASONIC VELOCITY STUDIES OF BINARY AQUEOUS SOLUTIONS CONTAINING AMIDES
}

\author{
Pramod P. Patil ${ }^{1,2,}$ Rupali S. Patil ${ }^{1}$, S. R. Patil ${ }^{3}$ and Amulrao U. Borse ${ }^{1, *}$ \\ ${ }^{1}$ School of Chemical Sciences, North Maharashtra University, Jalgaon-425001(M.S.) India. \\ ${ }^{2}$ Department of Chemistry, GulabraoDeokar College of Engineering, \\ Jalgaon-425001(M.S.) India. \\ ${ }^{3}$ Department of Chemistry A.S.C. College, Chopda, Dist. Jalgaon - 425107 (M.S.) India. \\ *E-mail: amulborse@gmail.com
}

\begin{abstract}
Viscosity $(\eta)$, Density $(\rho)$ and Ultrasonic velocities (U) are reported for binary mixtures of Formamide (FA), NMethylformamide (MFA) and N, N-Dimethylformamide (DMF) in an aqueous medium over an entire range of compositions at $298.15 \mathrm{~K}$ and atmospheric pressure. From the experimental data obtained, viscosity deviation $(\Delta \eta)$, deviation in isentropic compressibility $(\Delta \mathrm{Ks})$ and excess properties like excess molar volume $\left(\mathrm{V}^{\mathrm{E}}\right)$, excess intermolecular free length $\left(\mathrm{L}_{\mathrm{f}}^{\mathrm{E}}\right)$, excess available volume $\left(\mathrm{V}_{\mathrm{a}}^{\mathrm{E}}\right)$ and excess internal pressure $\left(\pi_{\mathrm{i}}^{\mathrm{E}}\right)$ have been calculated and are fitted to Redlich-Kister type polynomial equation. The results obtained are interpreted in terms of molecular interactions among the studied amide solutions. The deviation from ideal mixing law in all calculated parameters are negative except deviation in viscosity and deviation in excess internal pressure for $\mathrm{N}$ methylformamide and $\mathrm{N}, \mathrm{N}$-dimethylformamide-Water mixtures. This reveals the nature and magnitude of intermolecular interactions between unlike molecules and effect of $-\mathrm{CH}_{3}$ in amides. Substitution of $-\mathrm{H}$ by $-\mathrm{CH}_{3}$ at the $\mathrm{N}$ site caused a noticeable effect on the excess parameters.

Keywords: Viscosity, Density, Ultrasonic velocities, isentropic compressibility, excess free length, inter molecular interactions, Redlich-Kister polynomial equation.
\end{abstract}

(C) RASĀYAN. All rights reserved

\section{INTRODUCTION}

The Viscosity $(\eta)$, Density $(\rho)$ and Ultrasonic velocity (U) measurements find wide applications in characterizing the physicochemical behavior of liquid mixtures ${ }^{1-3}$ and in the study of molecular interactions. From the direct measurement of density, mixing parameter like excess molar volume could interpret which provides valuable information about the nature and type of molecular interactions in binary organic liquid mixtures ${ }^{4}$.Ultrasonic velocity and their related thermodynamic properties have been adequately employed in understanding the nature of molecular interactions in pure liquids $\mathrm{s}^{5}$ and binary mixtures. Studies on the molecular interactions from the knowledge of variation of thermodynamic parameters and their excess values with composition provide an insight to the molecular process ${ }^{6-8}$. The investigations regarding the molecular association in organic binary mixtures having amide group as one of the components is of particular interest, since amide group is highly polar and has large dipole moment can associate with any other group having some degree of polar attractions as well as they also hold structural similarities to proteins ${ }^{9}$. Water is protic solvent and is strongly associated due to highly polar $\mathrm{H}-$ $\mathrm{O}$ bonds. However, no thermodynamic studies have been conducted for binary mixtures of Formamide (FA), N-methylformamide (MFA) and N,N-dimethylformamide (DMF) in aqueous medium, hence experimental studies were carried out by the authors to predict the molecular interactions in amide-water mixtures through measurements of viscosity $(\eta)$, density $(\rho)$ and ultrasonic velocity (U) at $298.15 \mathrm{~K}$. The main purpose of this study is to elaborate the molecular interactions in the studied binary mixtures and

Rasayan J. Chem., 11(3), 1103 - 1112(2018)

http://dx.doi.org/10.31788/RJC.2018.1132078

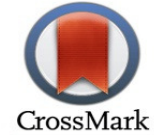


subsequently to determine the effect of the substituent length of amides. Liquid mixtures containing the amide functional group constitute an important tool in the interpretation of complex molecule of biological interest. In view of the importance mentioned, an attempt has been made to elucidate the molecular as well as structural interactions in the mixtures of amides in an aqueous medium at $298.15 \mathrm{~K}$. The excess functions are used to notify significant interactions in the studied binary mixtures.

\section{Materials and Methods}

\section{EXPERIMENTAL}

All the chemicals used in the present research work were analytical reagent (AR) grade having purity minimum assay of $99.9 \%$ purchased from Sigma-Aldrich, Germany and were used without further purification. The purity of the above chemicals was checked by density determination at $298.15 \mathrm{~K}$; the uncertainty is less than $\pm 1 \times 10^{-4} \mathrm{~g} \cdot \mathrm{cm}^{-3}$. The binary liquid mixtures of different known compositions were prepared in airtight, narrow mouth ground Stoppard bottles. The density, viscosity and ultrasonic velocity were measured as a function of the composition of the binary liquid mixture of distilled water with Formamide, N-Methylformamide and N, N-Dimethylformamide respectively at $298.15 \mathrm{~K}$.

\section{Density Measurements}

The density was determined using a high precision ANTON PAAR (Model: DMA5000) digital Densitometer. The weight of the sample was measured using an electronic digital balance with an accuracy of $\pm 0.01 \mathrm{mg}$ (Model: Shimadzu AUW-220D).

\section{Viscosity Measurements}

An Ubbelohde viscometer $(30 \mathrm{ml})$ was used for the viscosity measurements and efflux time was determined using a digital clock having an accuracy of $\pm 0.1 \mathrm{~s}$.

\section{Ultrasonic Velocity Measurements}

An ultrasonic interferometer having the frequency of $2 \mathrm{MHz}$ (Mittal Enterprises, New Delhi, Model: F81 ) with an overall accuracy of $\pm 0.1 \%$ has been used for velocity measurement. A Julabo F-32 Cryostat German made, has been used to circulate water through the double walled measuring cell made up of steel containing the experimental solution at the desired temperature with an accuracy of $\pm 0.01 \mathrm{~K}$.

\section{Theory and Calculations}

Excess volumes are determined by:

$\mathrm{V}^{\mathrm{E}}=\left(\mathrm{M}_{1} \mathrm{X}_{1}+\mathrm{M}_{2} \mathrm{X}_{2}\right) / \rho_{12}-\left(\mathrm{M}_{1} \mathrm{X}_{1}\right) / \rho_{1}-\left(\mathrm{M}_{2} \mathrm{X}_{2}\right) / \rho_{2}$

Viscosity of Binary Mixtures is determined by:

$\ln \eta_{\mathrm{m}}=\mathrm{X}_{1} \ln \eta_{1}+\mathrm{X}_{2} \ln \eta_{2}$

Deviation in Viscosity of Binary Mixtures is determined by:

$\Delta \eta_{\mathrm{m}}=\eta_{12}-X_{1} \eta_{1}-X_{2} \eta_{2}$

Deviation in isentropic compressibility have been evaluated by using the equation:

$\Delta \mathrm{k}_{\mathrm{S}}=\mathrm{K}_{\mathrm{S}}-\left(\Phi_{1} \mathrm{k}_{\mathrm{S} 1}+\Phi_{2} \mathrm{k}_{\mathrm{S} 2}\right)$

Where, $\mathrm{k}_{\mathrm{S} 1}$, $\mathrm{k}_{\mathrm{S} 2}$ and $\mathrm{K}_{\mathrm{S}}$ are isentropic compressibilities of liquid mixtures and $\Phi$ is volume fraction of pure components.

The excess properties $\mathrm{y}^{\mathrm{E}}$ are fitted by the method of nonlinear least squares to a Redlich-Kister type polynomial (5):

$\left.\mathrm{y}^{\mathrm{E}}=\mathrm{X}_{1} \mathrm{X}_{2} \sum \mathrm{Ai}\left(\mathrm{X}_{1}-\mathrm{X}_{2}\right)^{\mathrm{i}}\right)$

In each case, the optimum number of coefficients Ai was determined from an examination of the variation of standard deviation as calculated by: 
RASĀYAN J. Chem.

Vol. 11 | No. 3 |1103 - 1112 | July - September | 2018

$\sigma \mathrm{y}^{\mathrm{E}}=\left[\sum\left(\mathrm{y}^{\mathrm{E}}{ }_{\text {obs }}-\mathrm{y}^{\mathrm{E}} \text { cal }\right) /(\mathrm{n}-\mathrm{m})\right]^{1 / 2}$

Where, $n$ represents the number of experimental points and $m$ represents the number of coefficients in fitting the data.

$\mathrm{L}_{\mathrm{f}}^{\mathrm{E}}=\mathrm{L}_{\mathrm{fmix}}-\mathrm{X}_{1} \mathrm{~L}_{\mathrm{f} 1}-\mathrm{X}_{2} \mathrm{~L}_{\mathrm{f} 2}$

Excess values of the above parameters can be determined using:

$\mathrm{A}^{\mathrm{E}}=\mathrm{A}_{\exp }-\mathrm{A}_{\mathrm{id}}$

Where, $\mathrm{A}_{\mathrm{id}}=\sum \mathrm{Ai} \mathrm{Xi}, \mathrm{Ai}$ is any acoustical parameters and $\mathrm{Xi}$ the mole fraction of the liquid component.

Available volume $\mathrm{V}_{\mathrm{a}}=\left(\mathrm{V}_{\mathrm{m}}-\mathrm{V}_{0}\right)=\mathrm{V}_{\mathrm{m}}\left(1-\mathrm{U} / \mathrm{U}_{\mathrm{m}}\right)$

Where, $\mathrm{V}_{\mathrm{m}}=\mathrm{M} / \rho$, is the molar volume, $\mathrm{U}=$ Velocity, $\mathrm{V}_{0}=\mathrm{M} / \rho_{0}=$ molar volume at absolute zero temperature and $\mathrm{U}_{\mathrm{m}}=$ Schaaf's limiting value taken as $1600 \mathrm{~m} / \mathrm{s}$ for liquids.

\section{RESULTS AND DISCUSSION}

In the pure state, water has a high degree of self-association. This association decreases with increasing concentration of amides, when amides are mixed with water then there is an interaction between their individual functional groups $(\mathrm{H}-\mathrm{O}-\mathrm{H}$ and $-\mathrm{HN}-\mathrm{C}=\mathrm{O})$. The presence of electron withdrawing group in amides decreases electron densities on oxygen atom in water. The polarity of water is less hence their degree of self-association is less as compared to amides. The experimental values of density, viscosity and ultrasonic velocity for the aqueous solutions of studied amides at $298.15 \mathrm{~K}$ are given in Table-1.The values of excess thermodynamic and acoustical parameters for aqueous solutions of studied amides at $298.15 \mathrm{~K}$ are presented in Table- 2 and 3.

Table-1: Values of Molality (m), Density ( $\rho)$, Viscosity ( $\eta)$, Ultrasonic Velocity (U) for Binary Systems of FA, MFA, DMF (1) + Water (2) at 298.15K.

\begin{tabular}{c|c|c|c}
\hline $\begin{array}{c}\mathrm{m} \\
/ \mathrm{mol}^{\mathrm{k}} \mathrm{kg}^{-1}\end{array}$ & $\begin{array}{c}\rho \\
\left(\mathrm{gm} \cdot \mathrm{cm}^{-3}\right)\end{array}$ & $\begin{array}{c}\eta \times 10^{3} \\
\left(\mathrm{~N} \cdot \mathrm{s} \cdot \mathrm{m}^{-2}\right)\end{array}$ & $\begin{array}{c}\mathrm{U} \\
\left(\mathrm{m} \cdot \mathrm{s}^{-1}\right)\end{array}$ \\
\hline 0.00000 & 0.99704 & 0.8902 & 1497.70 \\
\hline 0.10321 & 0.9977 & 0.8928 & 1497.86 \\
\hline 0.20072 & 0.99834 & 0.8950 & 1500.88 \\
\hline 0.30832 & 0.99903 & 0.8975 & 1502.58 \\
\hline 0.40504 & 0.99965 & 0.8996 & 1504.11 \\
\hline 0.58532 & 1.00079 & 0.9038 & 1506.97 \\
\hline 0.60910 & 1.00094 & 0.9043 & 1507.34 \\
\hline 0.70500 & 1.00151 & 0.9065 & 1508.86 \\
\hline 0.80864 & 1.00215 & 0.9088 & 1510.50 \\
\hline 0.93966 & 1.00293 & 0.9118 & 1512.57 \\
\hline \multicolumn{4}{|c|}{$\mathrm{N}-\mathrm{Methylformamide+Water}$} \\
\hline 0.00000 & 0.99704 & 0.8902 & 1497.70 \\
\hline 0.10209 & 0.99727 & 0.9007 & 1500.28 \\
\hline 0.20687 & 0.99752 & 0.9115 & 1502.94 \\
\hline 0.30257 & 0.99776 & 0.9213 & 1505.36 \\
\hline 0.41497 & 0.99803 & 0.9329 & 1508.21 \\
\hline 0.50819 & 0.99825 & 0.9425 & 1510.57 \\
\hline 0.61377 & 0.99849 & 0.9534 & 1513.24 \\
\hline & & &
\end{tabular}

VISCOSITY, DENSITY AND ULTRASONIC VELOCITY

PramodP.Patilet al. 
RASĀYAN $J$. Chem.

Vol. 11 | No. 3 |1103 - 1112 | July - September | 2018

\begin{tabular}{c|c|c|c}
\hline 0.71210 & 0.99874 & 0.9636 & 1515.73 \\
\hline 0.80547 & 0.99896 & 0.9732 & 1518.09 \\
\hline 0.91062 & 0.99921 & 0.9841 & 1520.76 \\
\hline \multicolumn{4}{|c}{$\mathrm{N}, \mathrm{N}-$ Dimethylformamide+Water } \\
\hline 0.00000 & 0.99704 & 0.8902 & 1497.70 \\
\hline 0.09987 & 0.99693 & 0.9048 & 1501.95 \\
\hline 0.20105 & 0.99682 & 0.9218 & 1506.25 \\
\hline 0.30286 & 0.99673 & 0.9392 & 1510.58 \\
\hline 0.41502 & 0.99663 & 0.9562 & 1515.35 \\
\hline 0.51802 & 0.99656 & 0.9727 & 1519.73 \\
\hline 0.60646 & 0.99650 & 0.9865 & 1523.49 \\
\hline 0.70667 & 0.99644 & 1.0014 & 1527.75 \\
\hline 0.73868 & 0.99642 & 1.0066 & 1529.12 \\
\hline 0.91098 & 0.99634 & 1.0333 & 1536.44 \\
\hline
\end{tabular}

Table-2: Values of Molality $(\mathrm{m})$, Excess Volume $\left(\mathrm{V}^{\mathrm{E}}\right)$, Viscosity Deviations $(\Delta \eta)$, Deviations in Isentropic Compressibility $\left(\Delta \mathrm{K}_{\mathrm{S}}\right)$ for Binary Systems of FA, MFA, DMF (1) + Water (2) at 298.15K.

\begin{tabular}{c|c|c|c}
\hline $\begin{array}{c}\mathrm{m} / \\
\mathrm{mol} \cdot \mathrm{kg}^{-1}\end{array}$ & $\begin{array}{c}\mathrm{V}^{\mathrm{E}} \mathrm{x} 10^{6} \\
\left(\mathrm{~m}^{3} \cdot \mathrm{mol}^{-1}\right)\end{array}$ & $\begin{array}{c}\Delta \eta \times 10^{3} \\
\left(\mathrm{Kg} \cdot \mathrm{m}^{-1} \cdot \mathrm{s}^{-1}\right)\end{array}$ & $\begin{array}{c}\Delta \mathrm{K}_{\mathrm{S}} \times 10^{11} \\
\left(\mathrm{~m}^{2} \cdot \mathrm{N}^{-1}\right)\end{array}$ \\
\hline \multicolumn{4}{|c}{ Formamide + Water } \\
\hline 0.00000 & 0.0000 & 0.0000 & 0.00 \\
\hline 0.10321 & -0.0020 & -0.2113 & -0.02 \\
\hline 0.20072 & -0.0043 & -0.4192 & -1.70 \\
\hline 0.30832 & -0.0068 & -0.633 & -2.60 \\
\hline 0.40504 & -0.0092 & -0.8277 & -3.40 \\
\hline 0.58532 & -0.0134 & -1.1795 & -4.89 \\
\hline 0.60910 & -0.0140 & -1.2277 & -5.08 \\
\hline 0.70500 & -0.0158 & -1.4151 & -5.86 \\
\hline 0.80864 & -0.0181 & -1.6171 & -6.70 \\
\hline 0.93966 & -0.0207 & -1.8803 & -7.74 \\
\hline \multicolumn{5}{|c|}{$\mathrm{N}-\mathrm{Methylformamide}+\mathrm{Water}$} \\
\hline 0.00000 & 0.0000 & 0.0000 & 0.00 \\
\hline 0.10209 & -0.0041 & 0.8780 & -1.95 \\
\hline 0.20687 & -0.0085 & 1.7927 & -3.89 \\
\hline 0.30257 & -0.0125 & 2.6337 & -5.65 \\
\hline 0.41497 & -0.0174 & 3.6219 & -7.70 \\
\hline 0.50819 & -0.0214 & 4.4460 & -9.38 \\
\hline 0.61377 & -0.0257 & 5.3706 & -11.28 \\
\hline 0.71210 & -0.0303 & 6.2412 & -13.05 \\
\hline 0.80547 & -0.0343 & 7.0596 & -14.72 \\
\hline \multicolumn{5}{|c|}{1106} & \\
\hline & &
\end{tabular}


RASĀYAN $J$. Chem.

Vol. 11 | No. 3 |1103 - 1112 | July - September | 2018

\begin{tabular}{c|c|c|c}
\hline 0.91062 & -0.0388 & 7.9896 & -16.57 \\
\hline \multicolumn{4}{|c}{ N,N-Dimethylformamide+Water } \\
\hline 0.00000 & 0.0000 & 0.0000 & 0.00 \\
\hline 0.09987 & -0.0054 & 1.4672 & -2.93 \\
\hline 0.20105 & -0.0113 & 3.1788 & -5.83 \\
\hline 0.30286 & -0.0171 & 4.9421 & -8.72 \\
\hline 0.41502 & -0.0235 & 6.6617 & -11.87 \\
\hline 0.51802 & -0.0295 & 8.3230 & -14.73 \\
\hline 0.60646 & -0.0349 & 9.7153 & -17.18 \\
\hline 0.70667 & -0.0408 & 11.222 & -19.92 \\
\hline 0.73868 & -0.0430 & 11.7462 & -20.81 \\
\hline 0.91098 & -0.0533 & 14.4442 & -25.45 \\
\hline
\end{tabular}

Table-3: Values of Molality $(\mathrm{m})$, Excess Values of Free Length $\left(\mathrm{L}_{\mathrm{f}}^{\mathrm{E}}\right)$, Available Volume $\left(\mathrm{Va}^{\mathrm{E}}\right)$, and Internal Pressure $\left(\pi_{\mathrm{i}}^{\mathrm{E}}\right)$ for Binary Systems of FA, MFA, DMF (1) +Water (2) at 298.15K.

\begin{tabular}{c|c|c|c}
\hline $\begin{array}{c}\mathrm{m} \\
/ \mathrm{mol}^{\mathrm{k}} \mathrm{kg}^{-1}\end{array}$ & $\begin{array}{c}\mathrm{L}_{\mathrm{f}}^{\mathrm{E}} \times 10^{-10} \\
\mathrm{~m}\end{array}$ & $\begin{array}{c}\mathrm{V}_{\mathrm{a}}^{\mathrm{E}} \times 10^{-6} \\
\mathrm{~m}^{3} \cdot \mathrm{mol}^{-1}\end{array}$ & $\begin{array}{c}\pi_{\mathrm{i}}^{\mathrm{E}} \times 10^{6} \\
\mathrm{~N} \cdot \mathrm{m}^{-1}\end{array}$ \\
\hline 0.00000 & 0.0000 & 0.0000 & 000.00 \\
\hline 0.10321 & -0.0001 & 0.003 & -303.34 \\
\hline 0.20072 & -0.0010 & -0.027 & -808.32 \\
\hline 0.30832 & -0.0015 & -0.042 & -1197.82 \\
\hline 0.40504 & -0.0020 & -0.055 & -1548.11 \\
\hline 0.58532 & -0.0029 & -0.080 & -2183.78 \\
\hline 0.60910 & -0.0030 & -0.084 & -2268.78 \\
\hline 0.70500 & -0.0034 & -0.097 & -2609.35 \\
\hline 0.80864 & -0.0039 & -0.112 & -2970.32 \\
\hline 0.93966 & -0.0045 & -0.131 & -3438.88 \\
\hline \multicolumn{5}{|c|}{$\mathrm{N}-\mathrm{Methylformamide}+\mathrm{Water}$} \\
\hline 0.00000 & 0.0000 & 0.0000 & 000.00 \\
\hline 0.10209 & -0.0008 & -0.034 & 297.95 \\
\hline 0.20687 & -0.0017 & -0.070 & 679.35 \\
\hline 0.30257 & -0.0024 & -0.102 & 1039.66 \\
\hline 0.41497 & -0.0033 & -0.140 & 1449.75 \\
\hline 0.50819 & -0.004 & -0.172 & 1808.41 \\
\hline 0.61377 & -0.0048 & -0.208 & 2152.67 \\
\hline 0.71210 & -0.0056 & -0.242 & 2509.42 \\
\hline 0.80547 & -0.0063 & -0.275 & 2789.97 \\
\hline 0.91062 & -0.0071 & -0.312 & 3152.13 \\
\hline & $\mathrm{N}, \mathrm{N}-$ Dimethylformamide+Water \\
\hline
\end{tabular}


RASĀYAN $J$. Chem.

Vol. 11 | No. 3 |1103 - 1112 | July - September | 2018

\begin{tabular}{c|c|c|c}
\hline 0.00000 & 0.0000 & 0.0000 & 000.00 \\
\hline 0.09987 & -0.0012 & -0.052 & 399.62 \\
\hline 0.20105 & -0.0025 & -0.106 & 1098.31 \\
\hline 0.30286 & -0.0037 & -0.160 & 1911.13 \\
\hline 0.41502 & -0.0050 & -0.220 & 2440.1 \\
\hline 0.51802 & -0.0062 & -0.276 & 3042.19 \\
\hline 0.60646 & -0.0073 & -0.325 & 3451.66 \\
\hline 0.70667 & -0.0084 & -0.380 & 3881.37 \\
\hline 0.73868 & -0.0088 & -0.398 & 4030.65 \\
\hline 0.91098 & -0.0108 & -0.495 & 4869.15 \\
\hline
\end{tabular}

From Table-1 it is seen that, $\mathrm{V}^{\mathrm{E}}$ parameter become more negative with increasing concentration of amides.This is because more association of amides with water molecules increases with increasing concentration of amides.

The observed $\mathrm{V}^{\mathrm{E}}$ may be analyzed in terms of several effects, which may be categorized as physical, chemical and geometrical contributions ${ }^{5}$.The physical interactions comprise mainly dispersion forces and non-specific physical interaction giving a positive contribution. The chemical interaction involves the charge transfer complexes, resulting in contraction of volume, geometrical or structural contribution arising from the geometrical fitting of one component into other ${ }^{10}$.

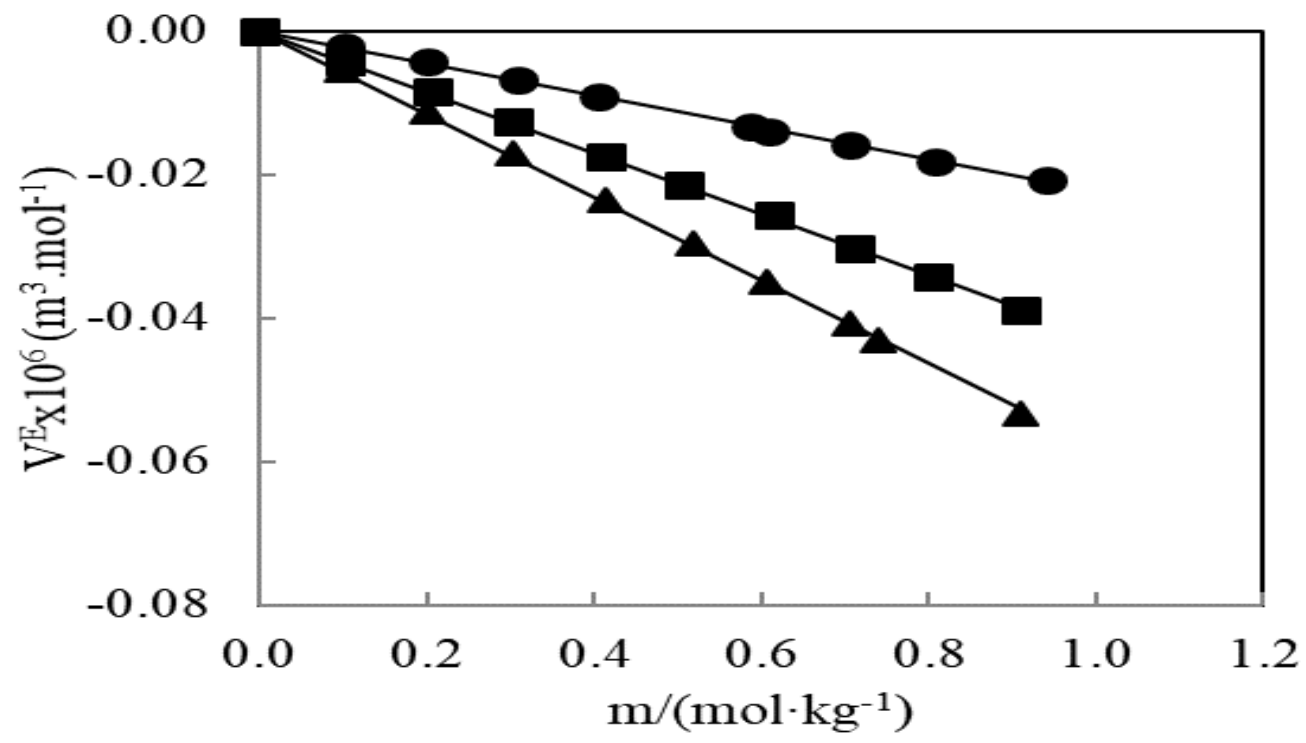

Fig.-1: Variation of Excess Volume $\left(\mathrm{V}^{\mathrm{E}}\right)$ as a Function of Molality $(\mathrm{m})$ of Amides in Aqueous Solutions at 298.15K.

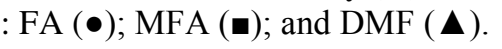

In all studied systems, no positive deviations of $\mathrm{V}^{\mathrm{E}}$ have been observed, attributed strong molecular interactions between the unlike molecules. Generally, when two solvents are mixed, the molecular interactions held will depend upon the type and nature of molecules. The positive excess volumes attribute structure breaking interactions while negative excess volumes attribute structure making interactions ${ }^{11}$. The $\mathrm{V}^{\mathrm{E}}$ parameter becomes more negative with increasing alkyl group on the $\mathrm{N}$-atom this is due to increase in basicity of amides with increasing alkyl group and signifies noticeable effect due to the substitution of $\mathrm{H}$ by $-\mathrm{CH}_{3}$ at the $\mathrm{N}$ site. The DMF (tert.amides) gives large $\mathrm{V}^{\mathrm{E}}$ than MFA (sec. amides) and later larger than FA (pri.amides).DMF does not show significant $\mathrm{H}$-bonding ability as DMF is not associated in a pure state, but they are sufficiently polar that the pure liquids presumed to be highly structured. However, FA and MFA are H-bonded, hence it could be considered that their $\mathrm{V}^{\mathrm{E}}$ values are 
consistent with substantial variation of amide self-aggregation in switching from pure liquids to water mixtures.Begonia Garcia and others observed $V^{\mathrm{E}}$ values for DMF-Water mixtures more negative than those of alcohol mixtures suggested that the structure of tertiary amides in water mixtures are even more compact than in pure state. Primary amides (FA) and secondary amides (MFA) are self associated to a greater extent than tertiary amides (DMF), which justify the more negative value of DMF ${ }^{12}$.

Figure-2 represents a plot of the variation of excess viscosity $(\Delta \eta)$ as a function of molality $(\mathrm{m})$ for all three studied aqueous amide systems at $298.15 \mathrm{~K}$, positive values are observed for MFA and DMF-Water systems, while negative values are observed for FA-Water system. This trend of positive $\Delta \eta$ values in increasing order often found in systems of polar unlike molecules, as in ethanol-water, dioxane-water ${ }^{13}$, diethylamine-water ${ }^{14}$ and DMSO-water ${ }^{15}$ and $\mathrm{N}, \mathrm{N}$-bisubstituted amides ${ }^{16}$. The positive values of $\Delta \eta$ in the MFA and DMF aqueous mixtures suggests strong hetero-association by multiple $\mathrm{H}$-bonding much in excess of weak association in the pure MFA and DMF. In contrast, Garcia observed the $\Delta \eta$ values are negative in amide-alkanol systems, except FA-Propanol-Pentanol and changed from negative to positive with increasing concentration of alcohol ${ }^{12}$. From the above discussion, it is revealed that secondary (MFA) and tertiary (DMF) amides interact strongly with water.

In the present investigation, the values of $\Delta \eta$ are more positive at higher concentration of the amides (Fig.-2) provide additional evidence for the existence of strong interactions like dipole-dipole type between components of liquid mixtures. The large positive values of excess viscosity can be attributed to the presence of the dispersion, induction and dipolar forces between the components while observed negative values infer the existence of dispersion, induction and dipolar forces. The magnitude of $\Delta \eta$ in MFA and DMF-Water system is positive and shows a linear increase with the concentration of the amides indicates that the specific interactions leading to the formation of complexes in liquid mixtures tend to make $\Delta \eta$ values positive.

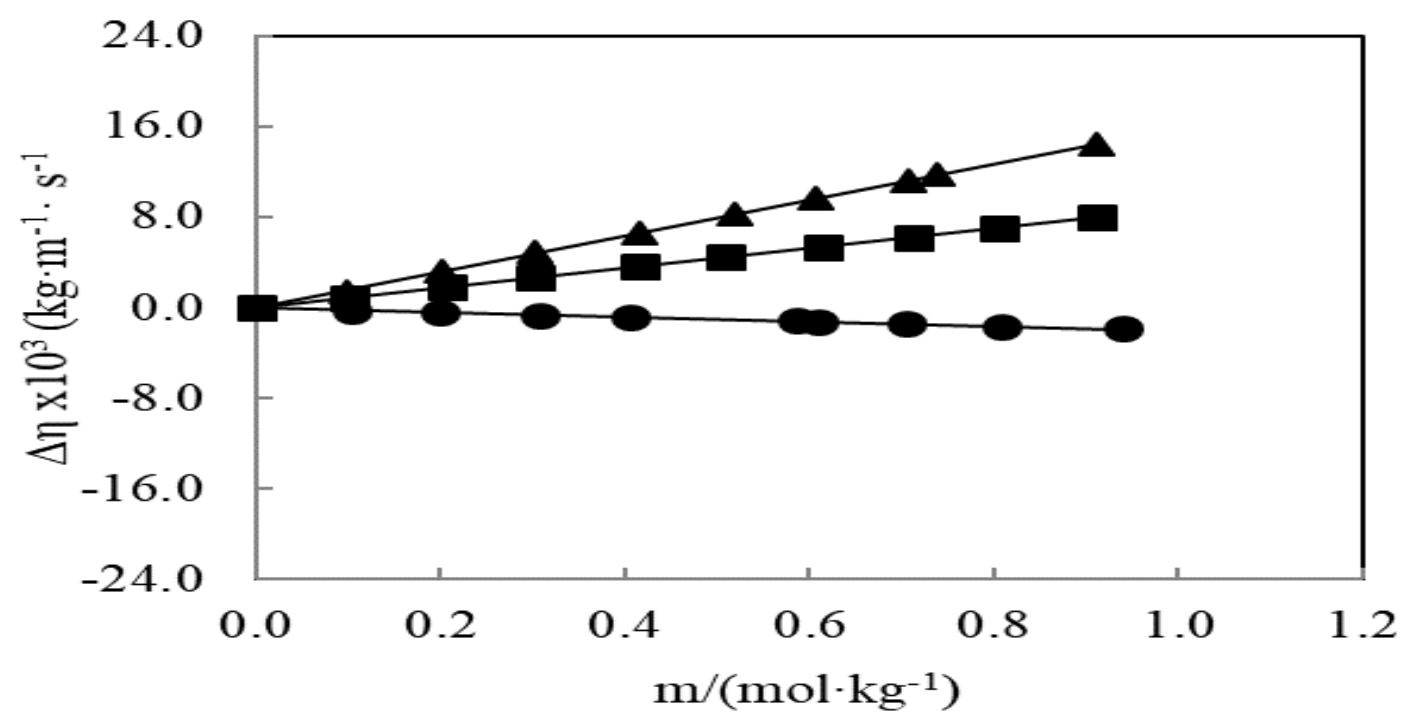

Fig.-2: Variation of Viscosity Deviation $(\Delta \eta)$ as a Function of Molality $(\mathrm{m})$ of Amides in Aqueous Solutions at

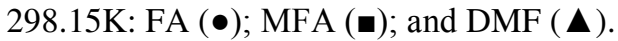

It is observed from Figure-3 that values of $\Delta \mathrm{Ks}$ are negative for all studied systems over the whole composition range at $298.15 \mathrm{~K}$. This behavior indicates specific interactions between amide and water molecules. The $\Delta \mathrm{Ks}$ values depend upon several contributions of physical and chemical nature ${ }^{17}$. More negative values suggest stronger interactions between unlike molecules like the formation of hydrogen bonds, the formation of charge transfer complexes and stronger dipole-dipole interactions between component molecules ${ }^{18}$. The deviations of bisubstituted amide (DMF) are greater in absolute values than mono-substituted (MFA) and these than un-substituted (FA) ${ }^{19}$. 
RASĀYAN J. Chem.

Vol. 11 | No. 3 |1103 - 1112 | July - September | 2018

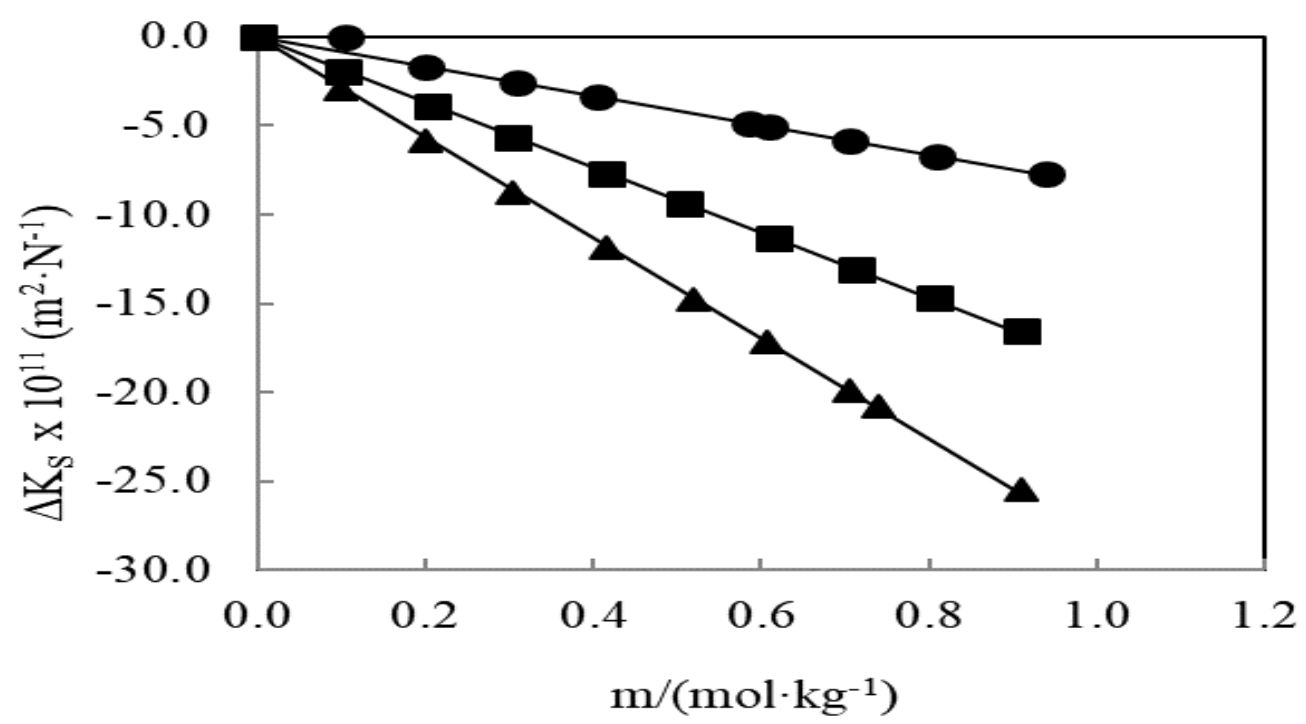

Fig.-3: Variation of Deviation in Isentropic Compressibility $\left(\Delta \mathrm{K}_{\mathrm{S}}\right)$ as a Function Molality $(\mathrm{m})$ of Amides in

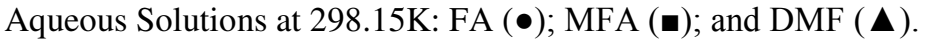

Table-1shows increase in ultrasonic velocity in solutions and it depends upon variations in molecular free length due to the interaction of components. Excess free length $\mathrm{L}_{\mathrm{f}}^{\mathrm{E}}$ have very small values and decrease with increasing concentration of solutes for all studied systems similarly, values of excess available volume $\left(\mathrm{V}_{\mathrm{a}}^{\mathrm{E}}\right)$ for all studied systems are found negative. The observed negative and positive values for excess parameters such as $\mathrm{L}_{\mathrm{f}}^{\mathrm{E}}, \mathrm{V}_{\mathrm{a}}^{\mathrm{E}}$ and $\pi_{\mathrm{i}}^{\mathrm{E}}$ respectively for amide-water mixtures shown in Table-3 indicates presence of specific interaction between water and amide molecules in these mixtures and is due to existence of dipole-dipole or dipole-induced interactions, proper interstitial accommodation and orientational ordering leading to more compact structure making negative contribution to $\mathrm{L}_{\mathrm{f}} \mathrm{E}^{\mathrm{a}} \mathrm{V}_{\mathrm{a}} \mathrm{V}_{\mathrm{a}}^{\mathrm{E}}$ for all systems and positive contribution except FA to $\pi_{\mathrm{i}}^{\mathrm{E}}(\text { Figure- } 4 \text { to } 6)^{20}$.

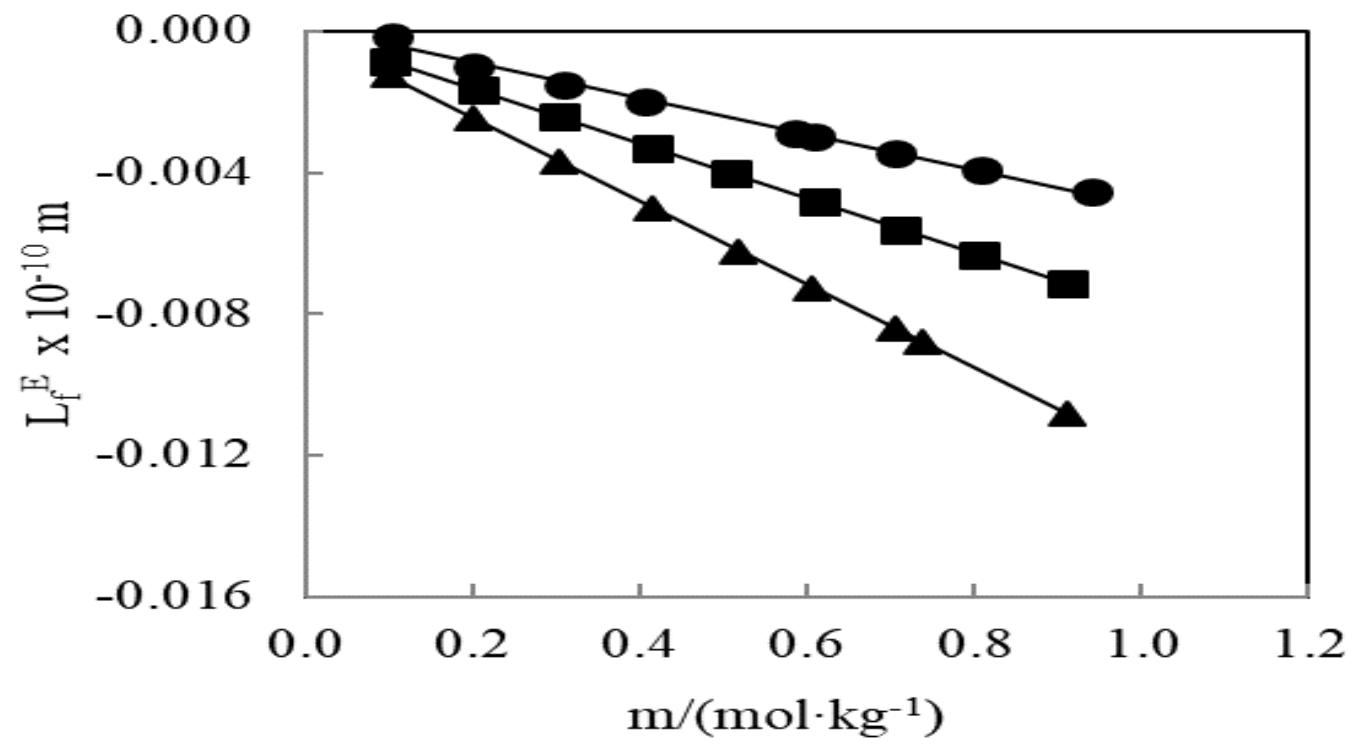

Fig.-4: Variation of Excess Free Length $\left(\mathrm{L}_{\mathrm{f}}^{\mathrm{E}}\right)$ as a Function of Molality $(\mathrm{m})$ of Amides in Aqueous Solutions at

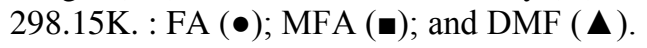

It is noticed from the Figure-6 that excess internal pressure $\left(\pi_{\mathrm{i}}^{\mathrm{E}}\right)$ values increased with increasing concentration of solute in mixtures of MFA and DMF-Water systems at $298.15 \mathrm{~K}$, indicating strong solute-solvent interactions in solution. The nature of $\pi_{\mathrm{i}}^{\mathrm{E}}$ plot is quite same as that of $\Delta \eta$ showing positive 
values of $\Delta \eta$ and $\pi_{\mathrm{i}}^{\mathrm{E}}$ for MFA and DMF-Water mixtures, while negative values for FA-Water mixtures provides evidence that, secondary (MFA) and tertiary amides (DMF) interact strongly with water.

Finally, the $\Delta \mathrm{k}_{\mathrm{S}}, \mathrm{Lf}_{\mathrm{f}}^{\mathrm{E}}$ and $\mathrm{V}_{\mathrm{a}}^{\mathrm{E}}$ values are negative over the entire composition range of the amides at $298.15 \mathrm{~K}$, these plots are linear with a negative slope. The values of $\Delta \mathrm{ks}_{\mathrm{S}}, \mathrm{L}_{\mathrm{f}}^{\mathrm{E}}$ and $\mathrm{V}_{\mathrm{a}}^{\mathrm{E}}$ follow the same order of interactions as that of $\mathrm{V}^{\mathrm{E}}$. FA shows weakest while DMF shows the strongest interactions. These negative values may be attributed to the existence of dipolar forces between unlike molecules as well as due to hydrogen bonding, dipole-dipole interactions etc. between water and amide molecules or due to the geometrical fitting of one component into another related to the difference in size and shape of the molecules ${ }^{18}$.

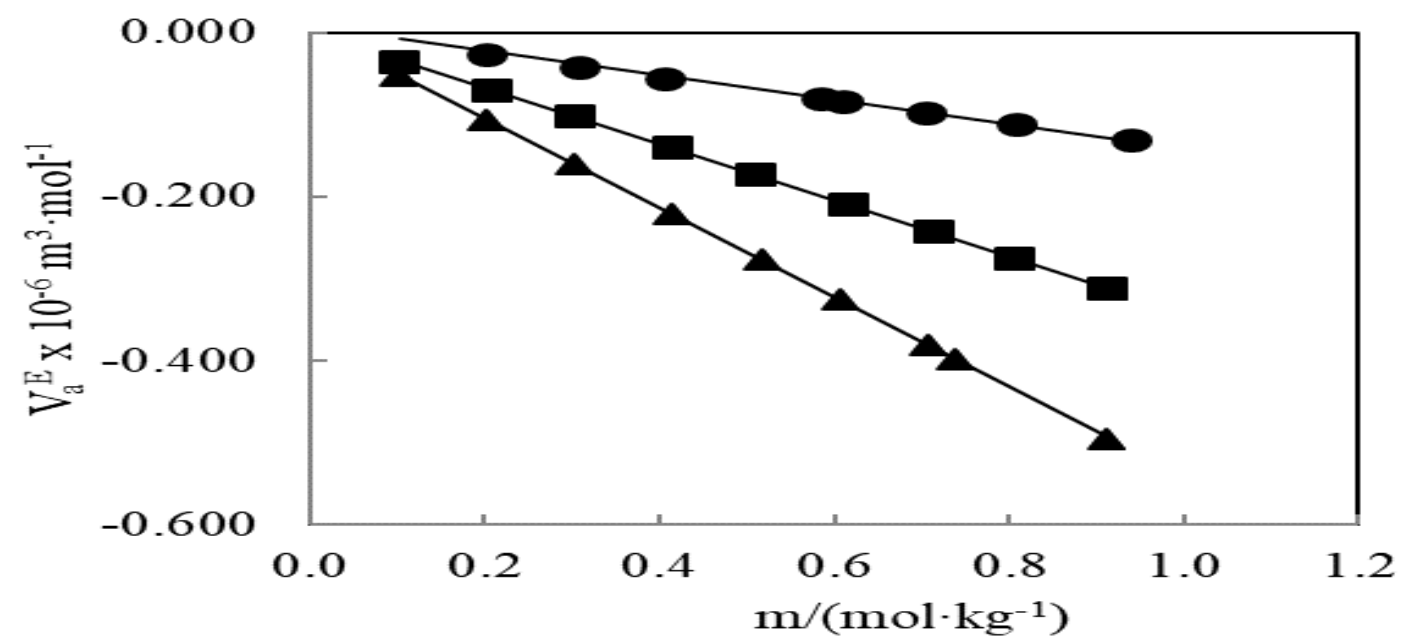

Fig.-5: Variation of Excess Available Volume $\left(\mathrm{V}_{\mathrm{a}}^{\mathrm{E}}\right)$ as a Function of Molality (m) of Amides in Aqueous Solutions at 298.15K: FA $(\bullet)$; MFA $(\boldsymbol{\bullet})$; and $\operatorname{DMF}(\boldsymbol{\Delta})$.

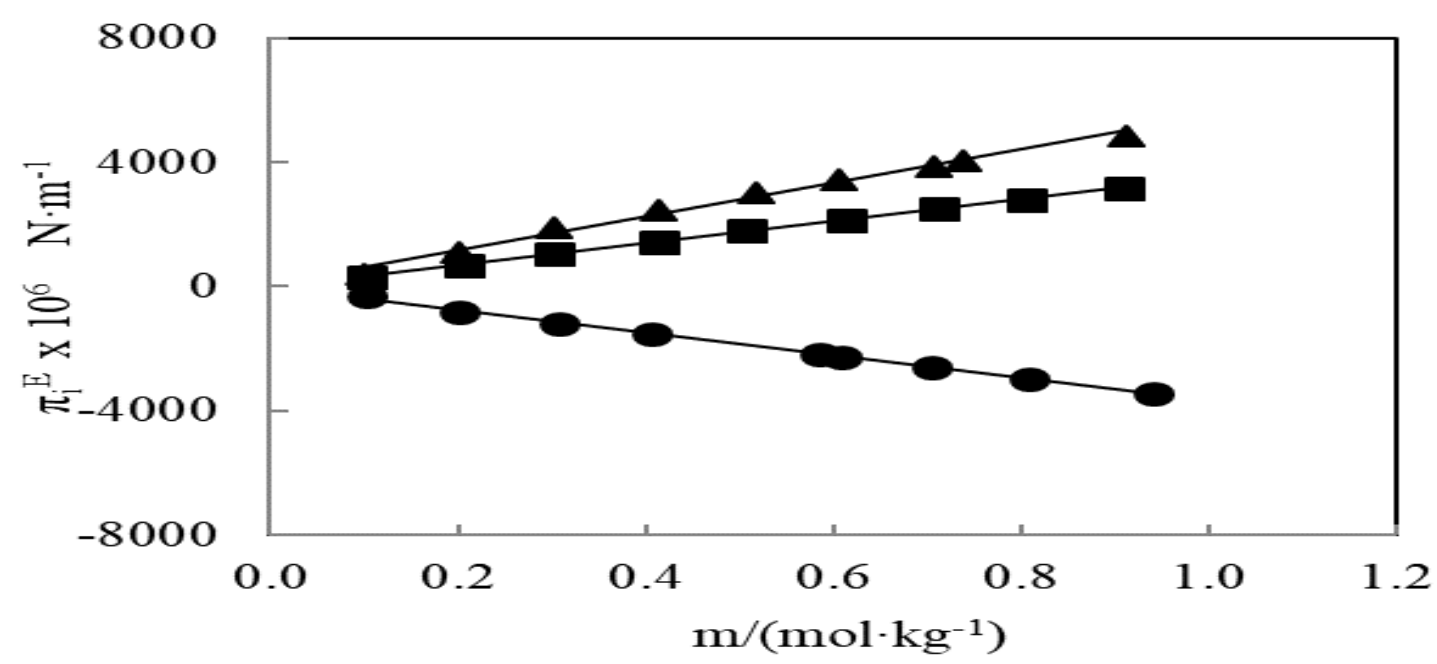

Fig.-6: Variation of Excess Internal Pressure $\left(\pi_{\mathrm{i}}^{\mathrm{E}}\right)$ as a Function of Molality $(\mathrm{m})$ of Amides in Aqueous Solutions at 298.15K: FA (•); MFA (๘); and $\operatorname{DMF}(\mathbf{\Lambda})$.

\section{CONCLUSION}

The experimental data of ultrasonic velocity $(\mathrm{U})$, density $(\rho)$ and viscosity $(\eta)$ are reported for binary aqueous mixtures of FA, MFA and DMF over the entire range of mole fractions at 298.15K.Calculated viscosity deviation, excess $\mathrm{V}^{\mathrm{E}}, \Delta \mathrm{k}_{\mathrm{s}}, \mathrm{L}_{\mathrm{f}}^{\mathrm{E}}$ and $\mathrm{V}_{\mathrm{a}}^{\mathrm{E}}$ shows large negative deviations for all the investigated binary systems. This reveals the existence of molecular interactions in the binary mixtures. The present investigation shows that greater molecular interaction exists in DMF-Water mixture which may be due to strong hydrogen bond formation and more basicity and weak molecular interaction that exists in the FA- 
water mixtures, which may be due to the dominance of dispersion forces and dipolar interaction between the unlike molecules.

\section{ACKNOWLEDGMENT}

Author Pramod P. Patil is thankful to North Maharashtra University, Jalgaon, M.S. (India), for sanction of financial assistance under 'Vice-Chancellor's Research Motivation Scheme' (VCRMS) and to the authority of Shri. Gulabrao Deokar College of Engineering, Jalgaon, M.S. (India), for providing all the necessary facilities for this research work.

\section{REFERENCES}

1. R. Mehta, H. Sanjnani, Indian J. Pure \& Appl.Phys.,38,762(2000).

2. R. Palani, A. Gutha, S. Saravanan, S. D. Tontapur, Rasayan J.Chem.,1(3),481(2008).

3. R. J. Fort and W. R. Moore, Trans. Faraday Society, 61, 2102(1965).

4. P. P. Patil, S. R. Patil, A.U. Borse, D.G. Hundiwale, Rasayan J. Chem., 4(3), 599(2011).

5. S. B. Kasare and B.A. Patdai, Indian J. Pure \& Appl. Phys., 25,180 (1987).

6. M. Ciler and D. Kesanovil, Hydrogen Bonding edited by Ha, dn, Zi, D Peragamon Press, London, 7(1957).

7. R. J. Large Man and W.S. Dundbar, J. Phys. Chem., 49, 428 (1945).

8. R. J. Fort and W.R. Moore, Trans. Faraday Society, 62, 1112 (1966).

9. M. H. Bhuiyan, A. W. Hakin, J. Solution Chem., 39,877(2010), DOI: 10:1007/s10953-010-9540-y.

10. S. R. Patil, U. G. Deshpande, A. R. Hiray, Rasayan J .Chem., 03(1), 66 (2010).

11. S. Jyostna, S. Nallani, J. Chem. Thermodyn., 38(3), 272 (2006), DOI:10:1016/j.jct.2005.05.06.

12. G. Begonia, R. Alcaldeand L. M. Jose, J. Phys. Chem., B 101, 7991(1997), DOI: 10.1021/jp9626374.

13. J. A. Geddes, J. Am. Chem.Soc.55, 4832 (1933), DOI: 10.1021/ja01339a016.

14. W. J. Barfield, Phys. Chem., 63, 1783, (1959).

15. J. Kenttamaa, J. Lindberg, J. S. Kemistil, B 33, 32 (1960).

16. P. Assorson, F. R. Eirich, J. Phys.Chem.,72, 2710(1968), DOI: 10.1021/j100854a003.

17. S. N. Pandharinath, P. S. Nikam, T.R. Mahale, J. Chem. Eng. Data,41(2),1055(1996), DOI: $10.1021 / \mathrm{je} 960090 \mathrm{~g}$.

18. A. Kumar Nain, Bull. Chem. Soc. Japan, 79(11), 1688(2006), DOI:10.1016/j.cjche.2014.12.003.

19. D. Papamatthaiakis, F. Aroni, V. Havredaki, J. Chem. Thermdyn., 40, 107(2008), DOI: 10.1016/j.jct.2007.05.015.

20. K. Rajgopal, S. Cheshilnath, Indian J. Pure \& Appl. Phys., 48 (5), 326(2010).

[RJC-2078/2018] 